\title{
An analysis of the cost of disability across Europe using the standard of living approach
}

\author{
José-Ignacio Antón ${ }^{1}$ - Francisco-Javier Braña ${ }^{2}$. \\ Rafael Muñoz de Bustillo ${ }^{2}$
}

Received: 20 October 2014 / Accepted: 30 May 2016 / Published online: 18 June 2016 (C) The Author(s) 2016. This article is published with open access at Springerlink.com

\begin{abstract}
This article presents for the first time a comparative study of the cost of disability for households in 31 European countries. In order to do so, we exploit the European Union Statistics on Income and Living Conditions, its special module on housing conditions for 2007 and 2012 and employ two alternative methodologies, one based on how difficult it is for households to make ends meet and the other related to the access of households to a set of services and assets. The comparative nature of the present analysis shows these national estimates of the cost disability from a broader perspective than previous research. One important finding of this study is that there is a significant diversity in the cost of disability across European countries, with Scandinavian countries at the top of the ranking and Eastern European states at the bottom. We discuss some possible explanatory reasons for the pattern of costs across countries found in our analysis.
\end{abstract}

\begin{abstract}
A preliminary version of the paper was published as a working paper of the Fundación de las Cajas de Ahorros (FUNCAS, No. 645) and the Department of Economics of the Johannes Kepler University Linz (No. 1508) and was presented at the 14th International Network for Economic Research Annual Conference in 2012 (Coimbra, Portugal) and at internal seminar at FLACSO-Ecuador in June 2015 (Quito, Ecuador). Antón thanks the financial support from the Spanish Ministry of Science and Innovation (research projects CSO2013-41828-R and CSO2013-47667-P) and the NORFACE research project GIWeS Globalisation, Institutions and the Welfare State. Muñoz de Bustillo gratefully acknowledges the funding from the Spanish Ministry of Science and Innovation (research project CSO2013-41828-R). We thank Fernando Antoñanzas, the editor Nezih Guner and two anonymous referees for very helpful and constructive comments that substantially improved the manuscript.
\end{abstract}

José-Ignacio Antón

jose.anton@jku.at

1 Department of Applied Economics, Johannes Kepler University Linz, Altenberger Straße 69, 4040 Linz, Austria

2 Departamento de Economía Aplicada, Facultad de Derecho, Universidad de Salamanca Spain, Campus Miguel de Unamuno, s/n., 37007 Salamanca, Spain 
Keywords Disability $\cdot$ Cost $\cdot$ Standard of living $\cdot$ Income $\cdot$ Welfare

JEL Classification I10 - I30

\section{Introduction}

Disability is far from being a marginal phenomenon in developed countries. ${ }^{1}$ According to Eurostat, $27.8 \%$ of European Union (EU) citizens above 16 years old suffered from a long-standing illness or health problem in 2014, whereas $8.6 \%$ reported experiencing strong limitations in their daily activities. ${ }^{2}$ Both in the Organization for Economic Co-operation and Development (OECD) and in the EU, there is strong concern about the issue and a mandate to promote and attain the full economic and social participation of people with disabilities. ${ }^{3}$ As a reflection of this concern, in the OECD and in the EU there is a variety of disability benefit systems, regulations and coverage. Some of these policies address the reintegration of disabled people into the labour market, while others aim to compensate individuals with disabilities. ${ }^{4}$ According to Eurostat, public social spending in this area reached a sizable $2 \%$ of GDP in the EU-28 in 2012, fluctuating from $0.7 \%$ in Cyprus to $4.4 \%$ in Denmark.

The aim of this paper is to offer an estimate of the "extra" costs of severe disability for households in 31 European countries (the 28 member states of the current European Union and Iceland, Norway and Switzerland), where the term "extra" refers to the over-cost faced by households with members with disabilities to reach a given level of well-being compared to similar households with non-disabled members. As far as we know, this is the first attempt to offer such an estimation using homogeneous data and the same methodology for a wide set of European countries. On top, we try to outline several plausible explanations for the differences in estimated costs across countries.

The estimation of the cost of disability in a large number of countries is relevant for both substantive and methodological reasons. Starting with the former, the estimation of the cost of disability for households will contribute to better evaluate the sufficiency of public compensatory disability policies. Furthermore, this type of analysis will allow better gauging the economic welfare implications of the future expected increase in disability rates related to the demographic change and the rise in life expectancy at

\footnotetext{
1 For a more global picture, with different insights into the situations of disabled people in developing countries, see WHO (2011).

2 In particular, this information comes from the following questions of the European Union Statistics on Income and Living Conditions: "People having a long-standing illness or health problem, by sex, age and activity status (\%)" and "Self-perceived limitations in daily activities (activity limitation for at least the past six months) by sex, age and activity status (\%)".

3 The OECD has a research field on disability, starting with a first report in 2003, opening a specific project of which the last outcome is a new report published in 2010, reviewing the policies of 13 countries. The European Commission has also published a European Disability Strategy 2010-2020 (European Commission 2010). Nevertheless, in both cases the aim is restricted to the labour market outcomes of people with disability, particularly eliminating barriers to their labour market integration and fostering higher participation rates among workers with disability.

4 For a review, see OECD (2003).
} 
older ages. ${ }^{5}$ On the methodological realm, the large number of countries included in the analysis will facilitate a better assessment of the appropriateness of the method of analysis used to estimate the cost of disability by looking at the similarity or dissimilarities of the estimates across countries, as well as the possible reasons behind them.

We characterise disability as a functional limitation that results not only from a medical condition of the body or the whole person but also from the relation of a person with the environment, which involves dysfunction at one or more of three levels: impairments, activity limitations and participation restrictions. ${ }^{6}$ The resulting loss of autonomy, physical or mental, prevents the performance of some of the activities of daily living, increasing the cost of reaching a given level of well-being.

Our approach to the cost of disability draws from the work of Sen (2004), who makes a distinction between two types of handicaps that tend to be associated with disability. On one hand, a disabled person may find it harder to get a job or to keep it, and he or she may receive a lower wage. Disability can even affect the acquisition or accumulation of human capital. ${ }^{7}$ On the other hand, because persons with disabilities have special needs, they face more difficulties than non-disabled people in achieving well-being from their resources or may need more income for the same activity. Sen calls the first one an "earning handicap" and the second one a "conversion handicap". The latter handicap is recognised in social protection systems in many countries, which provide through direct expenditure or tax expenditures and in other areas such as preferred parking or employment subsidies aimed to offset the higher costs associated with disability.

The starting point of our work is Sen's $(1985,1987)$ concept of distributive justice, based on equalising people's basic capabilities. For this author, the ultimate reference in redistributive policy is the standard of living, not the utility or the mere possession of goods. The issue is to establish an objective minimum standard that represents a good approximation to the real income level, considering that the standard of living is primarily an issue concerning lifestyle, rather than the means for its development. For Sen, the standard of living is a matter of functionings and capabilities. As it is well known, Sen's point of departure is the modern theory of the consumer (Lancaster 1966), according to which goods are not relevant in themselves, but because they incorporate features and properties that make them desirable. What matters is the use that each person can get from these characteristics, which depends on his or her capability to perform the functions to take advantage of the characteristics of each good. Therefore, given a set of goods, each individual, according to her/his capabilities, can convert its

\footnotetext{
5 In this respect, according to Eurostat, (European Health Interview Survey, EHSIS, 2012), the prevalence of disability among the EU28 population aged between 33 and 44 years old is $10.1 \%$, compared to $25.5 \%$ for those between 60 and 74 years old and $46.1 \%$ for those aged 75 and over.

6 Our concept of disability follows the so-called "bio-psycho-social model", according to which disability is the result of the interaction of the functional status of a person with his/her environment, taking into account the social aspects of disability and not seeing disability only as a "medical" or "biological" dysfunction. This is the approach adopted by the International Classification of Functioning, Disability and Health, endorsed by the 54th World Health Assembly (WHA) on 22nd May 2001 (resolution WHA 54.21). For a discussion of the definition and the measuring of disability, see OECD (2010).

7 This is illustrated, for example, by the work of She and Livermore (2007) for the United States.
} 
characteristics into different combinations of functionings, from which she/he obtains a certain level of welfare. The standard of living approach aims to determine the cost of disability by comparing households with disabled and non-disabled members with the same level of welfare and allowing the difference in income to determine the cost of disability.

Researchers have devoted some attention to the study of the costs of disabilities, though almost all the literature focuses on Anglo-Saxon countries. This body of research is also based on very different methodologies (discussed in the third section) and it relies exclusively on national studies, so the comparability of the different results found in the literature is far from ideal. Apart from the surveys of Indecon (2004), Tibble (2005) and Stapleton et al. (2008), one should highlight the works of Martin and White (1988), Matthews and Truscott (1990), Berthoud et al. (1993), Jones and O'Donnell (1995), Zaidi and Burchardt (2005), Kuklys (2005) and Wood and Grant (2010) for the United Kingdom, Indecon (2004) and Cullinan et al. (2011a) for Ireland, Saunders (2007) for Australia, She and Livermore (2007) and Mitra et al. (2009) for the United States, Wilkinson-Meyers et al. (2010) for New Zealand and Braña and Antón (2011) for Spain. In addition, Braithwaite and Mont (2009) estimate the cost of disability for two developing countries, Bosnia and Herzegovina and Vietnam.

Although a significant share of the mentioned studies are based on the standard of living approach, the overall results of this literature, discussed in more detail in the methodological section, are extremely difficult to summarise. This is because the authors rely on different definitions of disability and use different variables and econometric specifications to estimate the cost of disability, making their outcomes difficult to compare. The absence of comparative studies might also cast some additional doubts on the methodology followed, which is the reason why cross-country studies using a common methodology can contribute to test the appropriateness of the standard of living approach. Are the results for different countries roughly similar, or are the differences obtained consistent with economic theory and the idiosyncratic features of these countries? In this respect, the present work also aims to fill this gap.

Our study estimates the cost of disability — understood as suffering longstanding strong limitation in daily activities-for 31 European countries using two different strategies, one based on a subjective question about the household's ability to make ends meet and another related to the ownership of several assets. Overall, we find a pattern of diversity, with Scandinavian countries at the top and Eastern Europe nations at the bottom. Our results suggest that the cost of disability is positively correlated with per capita Gross Domestic Product (GDP) per capita, in line with an interpretation where disability implies a larger opportunity cost limiting the possibilities of making the best of participating in market activities of people with disabilities or their relatives or income transfers from relatives in other households. Also, we find that, on average, those countries with a larger cost of disability devote more social spending to this area, which could be a partial response of countries to the mentioned costs. Finally, this correlation is also found when looking at in-kind social spending, which might lead to an overestimation of the costs of disability in those countries that makes a higher budget effort in this sector. The article unfolds in four additional sections as follows. In Sect. 2, we describe the database used to estimate the cost of disability, 
pointing out its strengths and shortcomings. The third section presents and discusses the methodology followed in an estimation of the cost of disability. In Sect. 4, the results obtained in terms of the cost of disability in the 31 European countries are presented and discussed. Finally, Sect. 5 summarises the main conclusions obtained in the paper and outlines further lines of research.

\section{Data}

The database used in this research is the European Union Statistics on Income and Living Conditions (hereafter EU-SILC). ${ }^{8}$ Our aim is to study the cost of disability in 31 European countries, the current 28 member states of the EU plus Iceland, Norway and Switzerland, which are also available in the survey. Particularly, we use the crosssectional waves of 2007 and 2012 and its ad-hoc module on housing conditions, which contains valuable information we employ for constructing one of our wellbeing indicators.

The main advantage of this database is that it provides detailed information on household income and living conditions that is comparable across countries, jointly with considerable sample sizes that go from more than 3000 households in Iceland to almost 30,000 in Italy after all the data cleaning and processing work. Nevertheless, the EU-SILC also has several shortcomings. First, some information is not available for all countries, so the comparative analysis necessarily has to be restricted to those variables that are present in all member states. ${ }^{9}$ Second, and importantly, information in the database on disability is not as exhaustive and detailed as desirable. In particular, there are only two questions related to this issue. The first asks the interviewee if he or she has a chronic illness or health problem, while the second inquires as to whether the household member has been limited in his or her daily activity during the previous six months and to which extent. Although other studies in the literature, such as Zaidi and Burchardt (2005) — in some of their specifications — and Cullinan et al. (2011a), use similar questions to identify an individual with disability, the limitations of the survey in this sense have to be acknowledged. Third, information on disability is not available for people aged 16 years old or less, an important limitation of this study that one should bear in mind. In order to assess this issue, we carry out the analysis only for those households without children below that age. In any case, we have replicated all the analyses for the full sample households (with and without children), obtaining essentially the same results. ${ }^{10}$

The use of the panel data-which would have eventually allowed using fixedeffects techniques in order to control for unobserved heterogeneity was ruled out for three reasons. Firstly, the longitudinal version of the EU-SILC consists in a rotating panel, where $25 \%$ of the sample is renovated every year, so each 4-year panel roughly

\footnotetext{
8 Detailed information on the database, including methodological papers and national questionnaires, can be found at http://circa.europa.eu/Public/irc/dsis/eusilc/library.

9 For instance, those countries that collect detailed information on some types of issues (for instance, the gender pay gap) are not required to ask for the same information in the EU-SILC.

10 In fact, the correlation between the estimated costs across countries using the same methodology including and excluding children is above $95 \%$.
} 
implies $1 / 4$ of the households provided by each cross-section. In the second place, in order to construct one of our indicators of well-being we rely on several variables whose availability is restricted in the longitudinal version. Thirdly, partly related with the latter reason, there is very low within-household variability across time in both the left-hand- and right-hand-side key variables of interest (a well-being index using Principal Component Analysis we use for approximating to household well-being and disability indicators, respectively). The influence of the quite likely measurement error in both types of variables would be probably enlarged by the use of fixed-effects techniques, resulting in very inefficient and even inconsistent estimates biased towards zero. ${ }^{11}$ Also, it is worth mentioning that the other welfare variable used in the analysis ("ability of the household to make ends meet") is of an ordinal nature and fixed-effects techniques in this framework are far from being well-established. ${ }^{12}$

In order to make operative the concept of disability, we apply the following somewhat strict definition: a person is considered to be disabled if he or she reports having been strongly limited in his or her activities during at least the past six months. The share of population fitting that definition across European countries in our database in 2012 is presented in Table 1 . On average, $24.8 \%$ of the population would suffer some types of limitations in daily activities and $7.8 \%$, from strong limitations. For comparative and illustrative purposes, the table also depicts the share of people considered as disabled in two European-level surveys, the European Health Interview Survey (EHIS) 2012 and the ad-hoc module of the European Union Labour Force Survey (EU-LFS) 2011. These two surveys employ different definitions and are probably better equipped for measuring disabilities, but they do not properly capture household income and other indicators of well-being. The most remarkable facts are, first, that

\footnotetext{
11 In a linear regression framework, measurement error in the right-hand side results in both biased (attenuation bias, with estimates biased towards zero) and inefficient estimates, while the presence of this problem in the left-hand side variable implies less efficient estimates. With low within-household variation, the used of fixed effects can enlarge the problems generated by measurement error. See, among many others, Wooldridge (2010), Dieleman and Templin (2014) and the debate on measurement error in the context of the effect of union membership on earnings (Freeman 1984; Card 1996; Bollinger 1998; Swaffield 2001). Also, high inefficiency is very likely to be a major problem in a comparative work like the one presented here. In fact, when constructing all the possible 4-year panels using the longitudinal EU-SILC from 2004 to 2013, the within-household variability of the well-being index and the number of disabled household members represents roughly $10 \%$ and $33 \%$ of the total variation in the mentioned variables, respectively. For instance, in the case of disability, there are many households where the existence of intense long-term limitations in activity in the last 6 months among their members disappears from one year to another. Also, as it is common in all of these sorts of databases, income is measured since the 1st January to 31 st December of the year immediately before the survey, leading to some measurement error in this variable as well, as it might not exactly overlap with disability. It is expected that most of the variation (associated to between-households variation) is removed with the within-group transformation-or when computing differences - while most of the measurement error remains, becoming this issue proportionally more important than in the cross-sectional framework. Employing different sorts of techniques for removing unobserved heterogeneity (demeaning, regression in changes and correlated random effects), the resulting point estimates are extremely imprecise and in many cases very close to zero (which seems implausible as long as disability has an impact on labour market participation and even subjective well-being). These results are available from the authors upon request.

12 See Baetschmann et al. (2015) and Muris (2016) for a literature review. We also experimented with some linear models, obtaining similarly imprecise results as the ones reported for the variables based on the well-being index.
} 


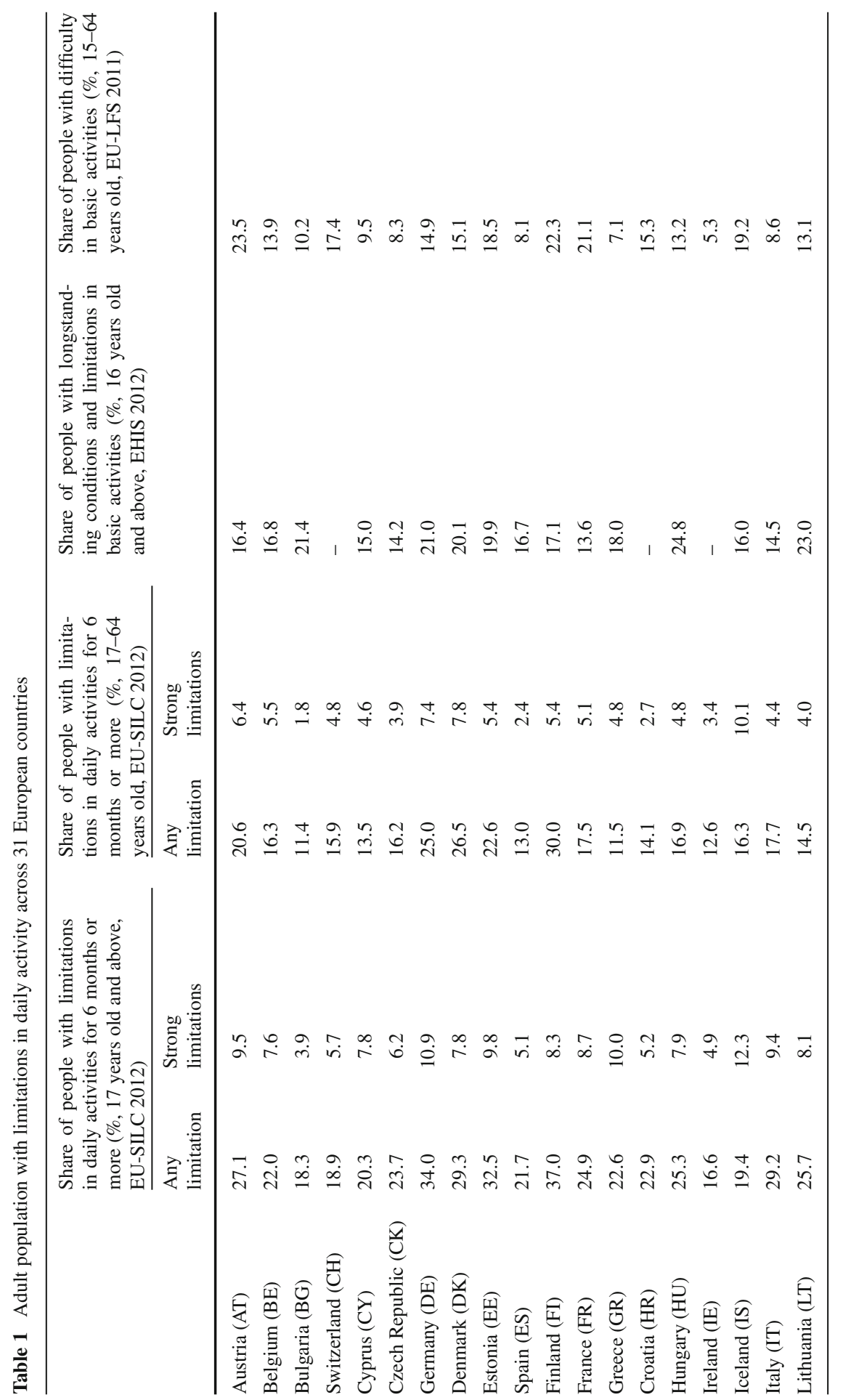




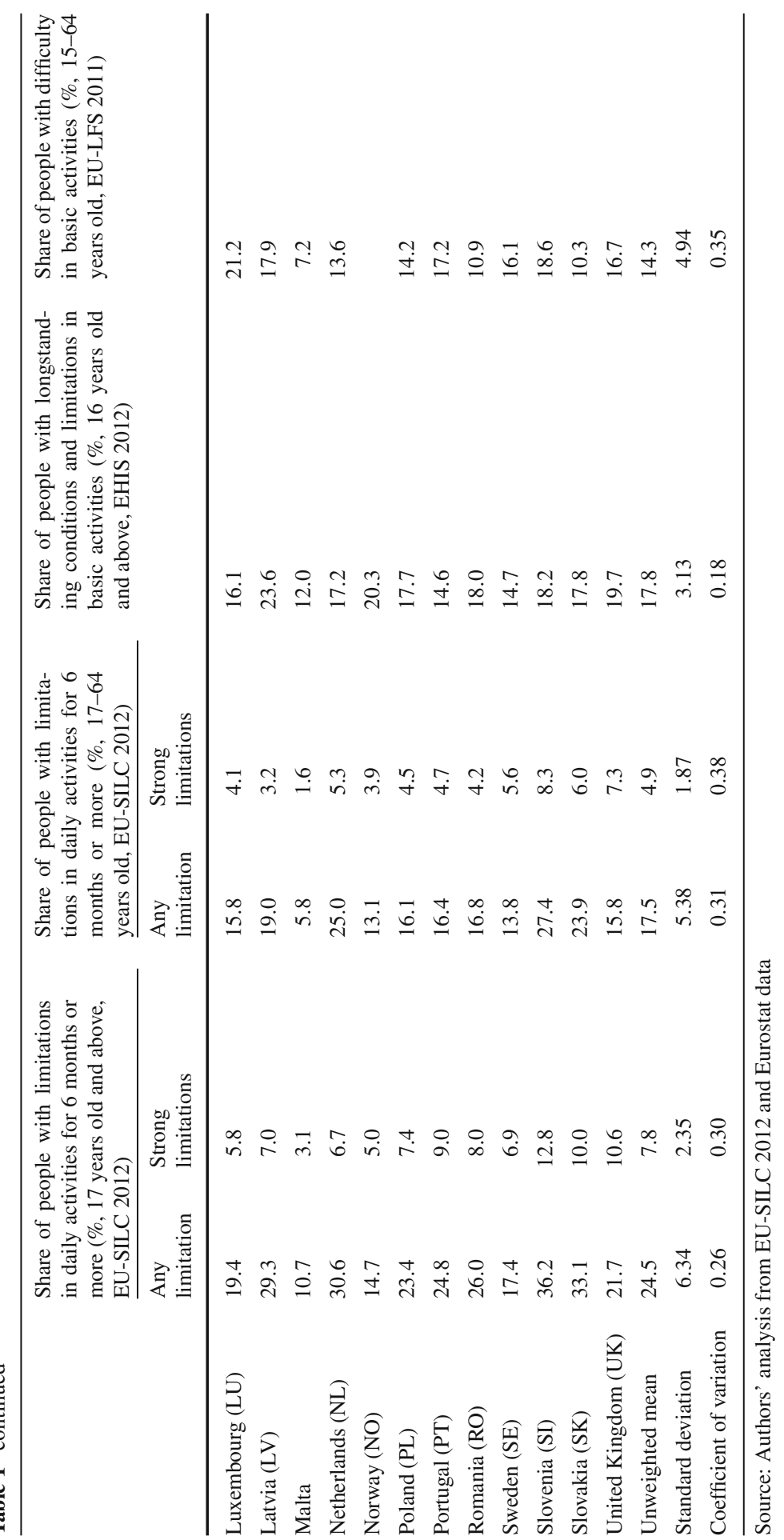


the dispersion of the share of disabled population across countries in the EU-SILC is larger than in the EHIS, but quite similar to the ones reported by the EU-LFS; and, second, there is a positive correlation between the percentage of people with some limitations in the EU-SILC and the EHIS 2012 and the EU-SILC and EU-LFS 2011 (coefficients of correlation of 0.29 and 0.51 , respectively). These differences in the definitions among surveys should be taken into account in the interpretation of the results, which should be made with caution, and in the comparisons to other previous research studies.

\section{Methodology}

The extra cost that disability imposes on households has been studied from different perspectives, which are associated with different research strategies. ${ }^{13}$ The subjective-direct approach, the most straightforward procedure, consists of asking disabled individuals (or experts) what are the costs of having a disability. The main limitation of this method is that respondents can hardly make an accurate estimation of how much they would spend on common goods everyone purchases if they were not disabled (Zaidi and Burchardt 2005). Some studies using this approach include Martin and White (1988) and Wood and Grant (2010) for the United Kingdom (UK), Wilkinson-Meyers et al. (2010) for New Zealand and the report of Indecon (2004) for Ireland, which offers a set of estimates for specific types of disability according to several assumptions and another one based on a detailed survey of disabled individuals (whose response rate was less than $20 \%$ and whose size was less than 300).

The second possible strategy (the comparative approach) relies on the study of the consumption patterns of both the disabled and the non-disabled population, identifying those items disabled people spend more on in order to control for income. This approach has usually been applied to evaluate the extra costs faced by disabled people associated with certain items, as Matthews and Truscott (1990) and Jones and O'Donnell (1995) do for the British case and Mitra et al. (2009) do for medical expenses in the United States. Although this method overcomes several of the limitations of the subjective-direct approach, it presents a serious shortcoming: the estimated cost of disability is constrained by the incomes of disabled individuals; in other words, they only report how much they actually spend, so it is not possible to measure the potential cost of disability.

The third and last approach is the so-called standard of living approach. This method is based on comparing the income levels of households with and without disabled members with the same level of welfare. The extra income required by households with disabled members to achieve that level of welfare represents the cost of disability. This method has received good reviews because of the robustness of the results obtained (Indecon 2004; Tibble 2005).

Furthermore, it is worth mentioning that some authors (Wilkinson-Meyers et al. 2010) have recently proposed benefitting from the strengths of each method. In other

13 For a survey on the different strategies, see, for instance, Indecon (2004), Wilkinson-Meyers et al. (2010) and WHO (2011). 
words, they propose using a mixed methodology that would involve looking at the specific needs of disabled individuals with the advice of a panel of experts, corroborating the estimation of the costs with a focus group of disabled individuals and, finally, validating the model using broad surveys.

The findings of the most relevant works on this topic are summarised in Table 2. As mentioned in the introduction of this article, most of this literature focuses on Anglo-Saxon countries (mainly the United Kingdom) and, because of the different strategies, disability definitions and variables and econometric specifications used to estimate the cost of disability, estimates vary widely across works and countries. This makes it very difficult to arrive at general conclusions about the cost of disability.

In this article, we follow the third methodology, the standard of living approach, (from now on subjective-indirect), which has been the most popular one in an otherwise sparse but growing literature (Zaidi and Burchardt 2005; Indecon 2004; She and Livermore 2007; Saunders 2007; Braithwaite and Mont 2009; Cullinan et al. 2011a). ${ }^{14}$ This method consists of estimating the effect of income and disability on welfare in order to determine how much income is needed to compensate for the existence of members with disabilities in the household, given a level of welfare. In practice, the method can be operationalised by estimating a model at the household level as the following one:

$$
W_{i}=\alpha+\beta Y_{i}+\chi N_{i}+\delta O_{i}+\phi X_{i}+\varepsilon_{i}
$$

where $Y_{i}$ is the income of household $i$ at 2010 prices, $W_{i}$ is a variable that denotes the welfare level or standard of living of household $i, N_{i}$ denotes the number of disabled members in the household, $O_{i}$, a dummy variable taking the value 1 if the disabled members live with no other adult (above 16 years old) and $X_{i}$ is a vector that includes an intercept and a set of variables capturing the socio-demographic characteristics of households (head sex, head age and head age squared, head marital status, head migrant status, head pensioner condition, household size and a dummy variable indicating if the survey corresponds to 2007 or 2012). ${ }^{15}$ We carry out the econometric analysis separately country by country.

In Eq. (1), the relationship between welfare, income and disability is linear, which implies that the cost of having a member with a disability in the household living without any other adult in terms of income is given by a fixed monetary amount represented by $-\chi / \beta$. In such a specification, disability has a fixed effect on the level of welfare given by $\chi<0$, while the effect of income on welfare is represented by $\beta>0$. Therefore, the amount of income that neutralises the negative effect of disability on household welfare is given by (minus) the ratio of both coefficients. ${ }^{16}$

\footnotetext{
14 The fourth strategy mentioned above is unfortunately beyond our means. In a comparative analysis of 31 countries as the one presented in this paper, such methodology would require, among other things, corroborating the estimation of the costs with a focus group of disabled individuals in 31 countries.

15 The set of variables included in the analysis is similar to the ones used by other works in the literature such as Indecon (2004), Zaidi and Burchardt (2005) and Cullinan et al. (2011a). It is also worth mentioning that in more than $80 \%$ of the cases, households with disabled members only include a person with disabilities. 16 See Zaidi and Burchardt (2005) or Cullinan et al. (2011a) for a more detailed description of the methodology.
} 


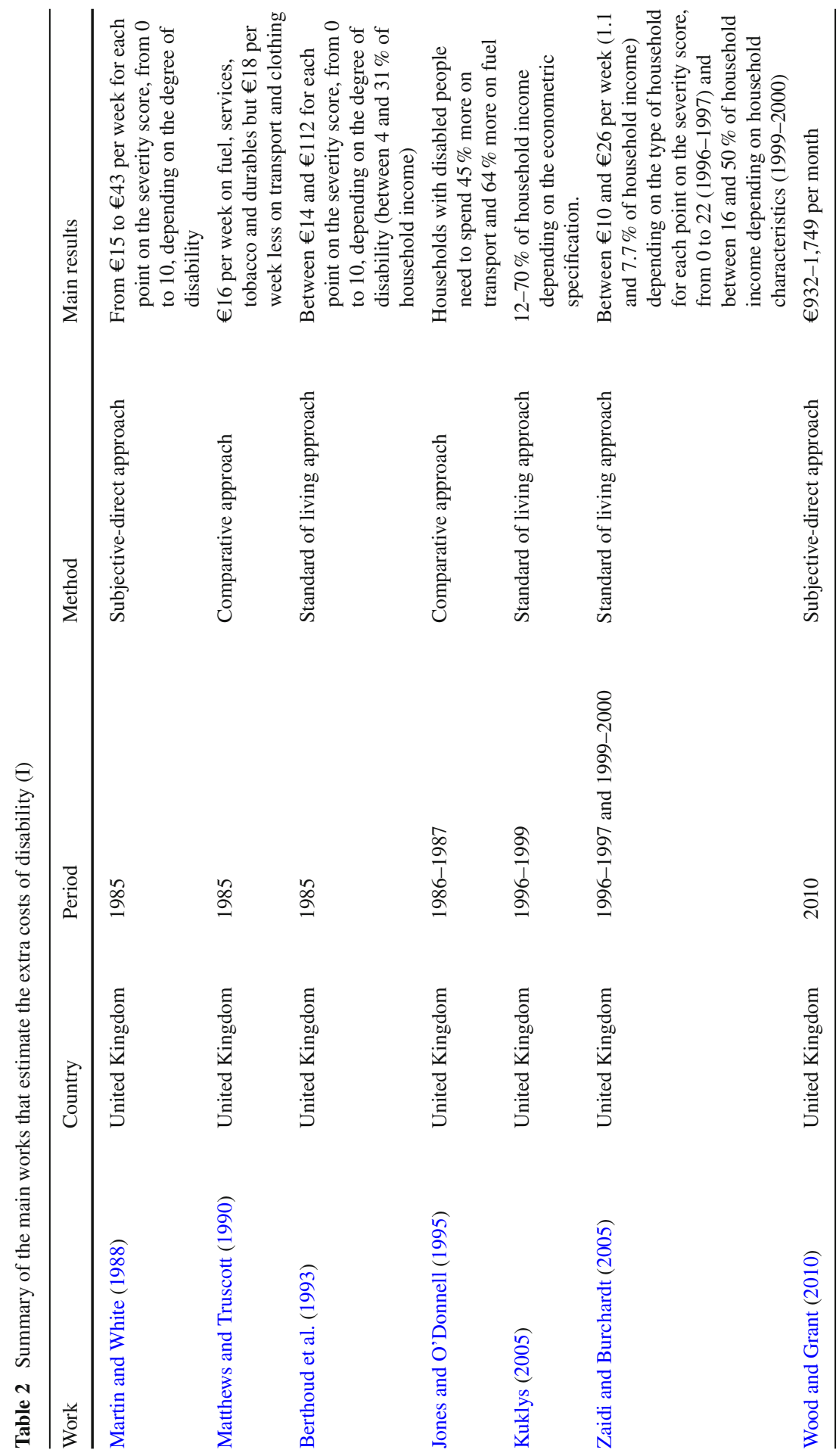




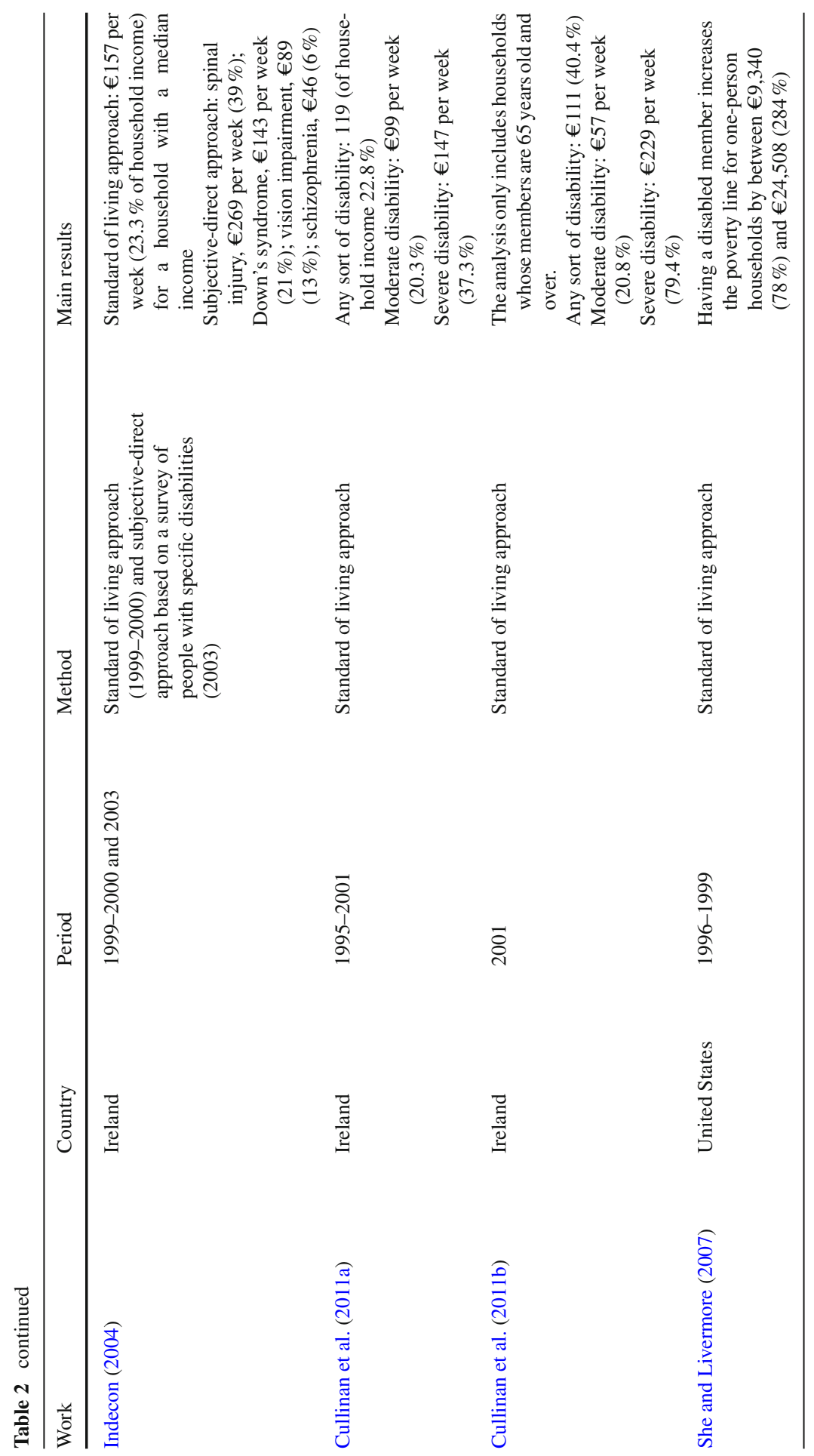




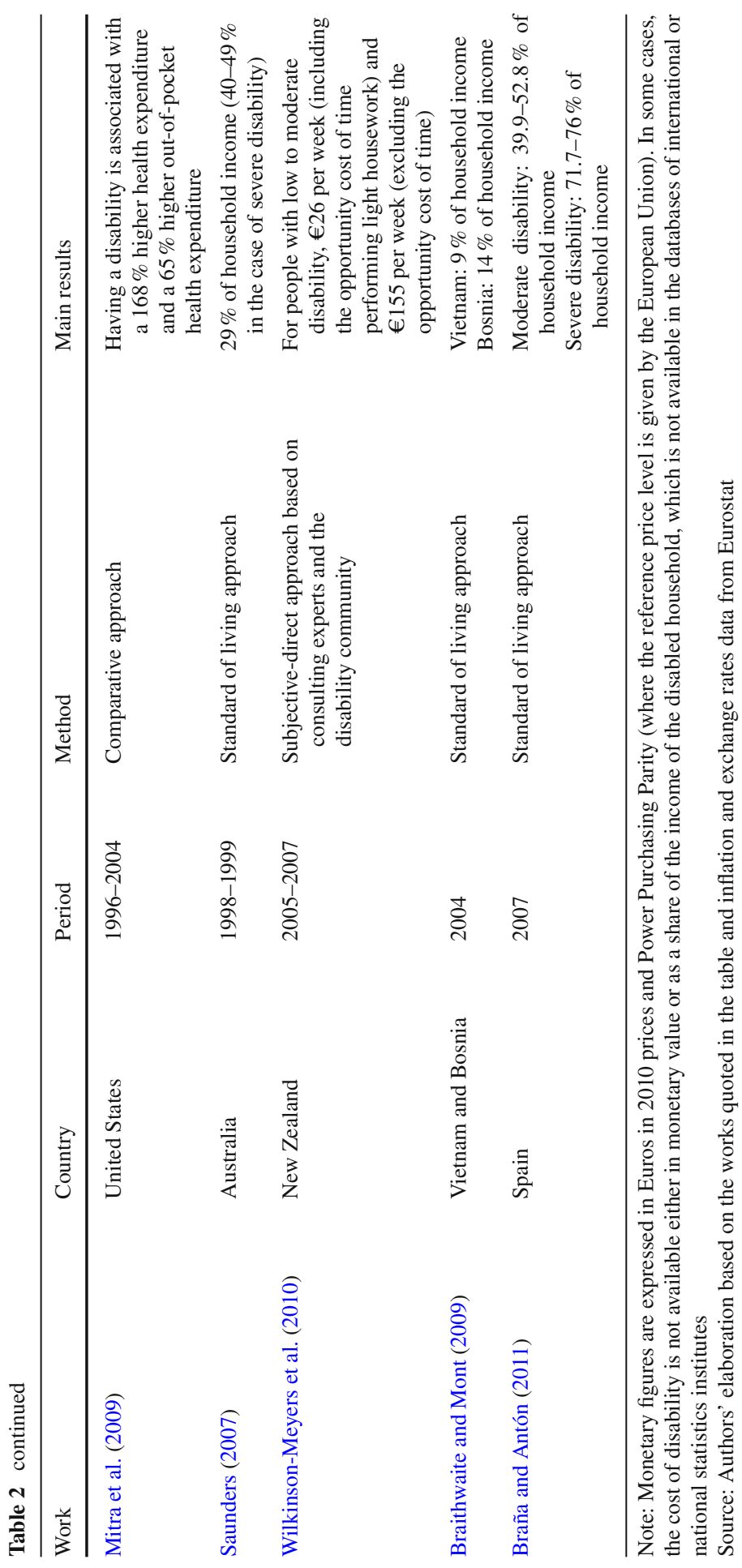


Obviously, such a relationship can be modelled in alternative ways, including income in logs, squared or even interactions between both variables. A specification including income in logs, for instance, assumes not only decreasing returns to income in terms of welfare but also that the cost of disability is a constant proportion of income. We finally use an econometric specification that includes income in logs because of two reasons. First, it makes interpretation and comparison with most of papers in the literature easier, since this article has comparative purposes and such model has been the most used by far in previous research. Second, it seems to be the model that best fits the data in many cases, both using measures as the Akaike and Bayesian Information Criteria in the case of models estimated by maximum-likelihood and $\mathrm{R}^{2}$ in linear regressions.

One of the main issues of concern in the standard of living approach is how to determine households' levels of welfare disregarding income data. Following the spirit of Zaidi and Burchardt (2005), we proceed in two ways. First, we consider being a welfare indicator the response given by household heads to the question regarding the ability of the households to make ends meet with their current incomes. The possibilities for answering this question were "with great difficulty", "with difficulty", "with some difficulty", "fairly easily", "easily" and "very easily". In order to fit the model, we use an ordered logit (with heteroscedasticity-robust standard errors), which assumes the existence of an underlying and unobservable variable (welfare), which is codified into intervals that determine the categories that are fully observed by the researcher. As it is well known, this type of model is estimated using maximum likelihood methods. The phrasing of the question used to construct the welfare indicator is similar to the questions used in comparable studies for other countries. ${ }^{17}$ Second, we construct an indicator that aims to capture welfare using information on the assets and other features of households. One possibility is to simply count the number of assets and fit a negative binomial regression model. However, this method shows problems of convergence for some countries, thus hindering the comparability of the analysis. ${ }^{18}$

Another option is grouping the assets and considering a certain number of them to determine a given level of welfare. For example, four items can be interpreted in terms of a low level of welfare and 21 items as a larger level. This strategy, used by Zaidi and Burchardt (2005), Braithwaite and Mont (2009) and Cullinan et al. (2011a),

17 This question is similar to the one included in the European Community Household Panel used by Cullinan et al. (2011a). Zaidi and Burchardt (2005) also use a similar question taken from the British Household Panel Survey, along with another one asking whether the interviewed household can save. She and Livermore (2007) and Saunders (2007) test several questions in the same spirit (food insecurity or ability to pay bills, meet expenses, pay rent or mortgage and get medical care, among others).

18 As it is well known, these types of models are estimated by maximum likelihood, involving the maximisation of complex log-likelihood functions. In practice, this process is a search of the maximum by trial and error. In some countries, the proposed specifications do not converge (and we rule out that this problem is associated with multicollinearity problems). Thus, given that our article has a comparative purpose, we decide not to use these types of models. Other more simple alternatives, such as the Poisson model, are ruled out because of the strong assumptions they entailed. In any case, it is also worth mentioning that in the work of Braña and Antón (2011) for Spain, the results obtained using the PCA component as dependent variables are similar to the one obtained using a binomial negative regression where the number of items was the outcome of interest. Moreover, in this research, the welfare index -and the final results- obtained by PCA is fairly robust to different ranges of goods and household characteristics. 
gives rise to problems of convergence similar to those found in the negative binomial regression. We therefore use a third and quite pragmatic approach: we carry out a principal component analysis (PCA) of 22 different items/assets or dimensions of the households in the sample. All these items are found to be positively correlated with household income.

The first principal component obtained by this procedure is a continuous variable which accounts for as much of the variability of the data as possible and can be considered to be a good way of estimating household welfare (Filmer and Pritchett 2001), is taken as the dependent variable of Eq. (1), which is thus estimated using Ordinary Least Squares (OLS) with robust standard errors. One of the main advantages of this method is that, as long as the first component aims to capture as much as variance as possible, it proves to be quite robust to the inclusion of one or another item. We also estimate a well-being index using a multiple correspondence analysis (MCA), finding that the correlation at the household level between both indexes (the one obtained using the PCA and the other by the MCA) is over $99 \%$. The following items, those on which there is available information in the EU-SILC, are selected to carry out the analysis: ${ }^{19}$

- No arrears on the payment of mortgage or rents.

- No arrears on utility bills.

- No other arrears.

- Capacity to afford to pay for a one-week annual holiday away from home.

- Capacity to afford a meal with meat, chicken, fish or vegetarian equivalent every second day.

- Capacity to meet unexpected financial expenses.

- To have a telephone.

- To have a colour television set.

- To have a computer.

- To have a washing machine.

- To have a car.

- To have toilet at home.

- To have a shower at home.

- Not to have any natural light problems at home.

- Not to have any noise problems at home.

- Not to have any pollution or environmental problems.

- No crime or violence in the area.

- Not to have a leaking roof, damp walls, floors or foundation or rot in window frames and floor.

- Be the owner of the accommodation.

- To be able to keep home adequately warm.

- To have enough space at home.

- Adequate electrical installations.

19 We have to rule out other potentially interesting items -like having adequate plumbing or the proximity of some facilities- because the percentage of missing values reaches more than $20 \%$ in some countries. 
The use of two different methodologies - a choice also made by Zaidi and Burchardt (2005)- aims to assess how robust the findings are to the approach chosen to measure household welfare. In the first case, the question is more subjective (since the household self-reports its ability to make ends meet), while the second one can be considered to be a more objective approach, since it only relies on a household's assets and services. Nevertheless, even in the latter option, the welfare variable can be contaminated by differences in preferences.

\section{Results}

Before presenting the results of the empirical analysis, we look at the main descriptive statistics, namely the proportion of households with members with disability, the average number of disabled household members and the proportion of disabled household members living with other adults (Table 3). In contrast to the information showed in Table 1, the statistics showed in Table 3 correspond to households and the final samples employed in the econometric analysis.

The data show a larger dispersion in the average number of household members with people with disabilities compared with differences found in terms of the people with disabilities reproduced in Table 1 (the coefficients of variation are 0.42 and 0.30 respectively). In a relatively small number of countries (the Scandinavian countries plus the Netherlands, Iceland and Slovenia), the percentage of the population with disabilities (as defined in this paper) is roughly equivalent to the percentage of households with people with disabilities. The rest have a much larger percentage of households with members with disabilities compared with the population with disabilities. This fact reflects the existence of different living arrangements across countries.

The estimated costs of disability (with their corresponding $95 \%$ confidence intervals) in the 31 countries included in this study are displayed in Fig. 1. The bar graphs depict the estimates of the term $-\chi / \beta$, where $\chi$ is the number of disabled household members and $\beta$ is the coefficient associated with income (in logs). The error bars, denoting $95 \%$ confidence intervals, are computed from the standard error of the mentioned term. ${ }^{20}$

Several conclusions can be drawn about the estimated cost of disability for households (extra income needed to reach the same standard of living in two otherwise equivalent households but for the existence of members with disabilities) reproduced in both figures, the first using the question on the resources to make ends meet and the second using the assets approach. First, it should be mentioned that, overall, the magnitude of the costs is reasonably similar in both models, between 17 and $99 \%$ of household income in the first approach and between 16 and $155 \%$ according to the second one. Nevertheless, there are important differences for particular countries, such

\footnotetext{
20 The detailed econometric results-which comprise 62 econometric analyses ( 2 models and 31 countries) - are not reproduced in the text for brevity, but the complete regressions, including the coefficients for the control variables, are available from the authors upon request. We have also estimated the cost of a member with disabilities when he or she lives with other adults, which is given by $-(\chi+\delta) / \beta$. These costs are logically lower, but they are highly correlated with the costs presented in Fig. 1 and Table 4. These results are available from the authors upon request.
} 
Table 3 Main descriptive statistics of the database (based on households)

\begin{tabular}{|c|c|c|c|}
\hline Country & $\begin{array}{l}\text { No. of } \\
\text { households }\end{array}$ & $\begin{array}{l}\text { Average number of disabled } \\
\text { household members (with } \\
\text { strong limitations in activity) }\end{array}$ & $\begin{array}{l}\text { Share of households with } \\
\text { disabled members where } \\
\text { disabled members live } \\
\text { with other adults }(\%)\end{array}$ \\
\hline Austria (AT) & 9540 & 0.21 & 57.1 \\
\hline Belgium (BE) & 8266 & 0.16 & 62.8 \\
\hline Bulgaria (BG) & 7254 & 0.10 & 69.4 \\
\hline Switzerland (CH) & 5439 & 0.13 & 64.0 \\
\hline Cyprus (CY) & 4830 & 0.23 & 74.8 \\
\hline Czech Republic (CK) & 14,202 & 0.13 & 59.5 \\
\hline Germany (DE) & 19,532 & 0.18 & 64.7 \\
\hline Denmark (DK) & 7505 & 0.03 & 61.1 \\
\hline Estonia (EE) & 7427 & 0.26 & 65.5 \\
\hline Spain (ES) & 17,699 & 0.19 & 74.0 \\
\hline Finland (FI) & 14,743 & 0.08 & 56.6 \\
\hline France (FR) & 15,525 & 0.17 & 61.3 \\
\hline Greece (GR) & 8070 & 0.24 & 63.4 \\
\hline Croatia (HR) & 4650 & 0.15 & 61.3 \\
\hline Hungary (HU) & 14,785 & 0.26 & 60.7 \\
\hline Ireland (IE) & 6913 & 0.16 & 61.0 \\
\hline Iceland (IS) & 3184 & 0.10 & 64.5 \\
\hline Italy (IT) & 28,712 & 0.19 & 65.7 \\
\hline Lithuania (LT) & 8046 & 0.24 & 63.6 \\
\hline Luxembourg (LU) & 6197 & 0.14 & 71.3 \\
\hline Latvia (LV) & 8040 & 0.22 & 54.1 \\
\hline Malta & 3047 & 0.09 & 70.2 \\
\hline Netherlands (NL) & 13,450 & 0.07 & 51.8 \\
\hline Norway (NO) & 7653 & 0.06 & 57.1 \\
\hline Poland (PL) & 17,563 & 0.20 & 69.0 \\
\hline Portugal (PT) & 7658 & 0.31 & 66.4 \\
\hline Romania (RO) & 12,043 & 0.21 & 56.6 \\
\hline Sweden (SE) & 8638 & 0.07 & 63.7 \\
\hline Slovenia (SI) & 12,763 & 0.12 & 77.6 \\
\hline Slovakia (SK) & 7619 & 0.28 & 66.6 \\
\hline United Kingdom (UK) & 11,957 & 0.21 & 52.1 \\
\hline
\end{tabular}

Source: Authors' analysis from EU-SILC 2007 and 2012

as the Netherlands, Denmark, Sweden, Norway or Malta (some of them with not so large samples). Second, in general (7 out of 31 cases), the subjective model produces a lower cost of disability. This is an interesting result in itself that can be interpreted in terms of the existence of a process of downward adaptation of the expectations of households with disabled people that allows them to make ends meet with lower increases in household income (to compensate for the higher needs of disabled people) 
(Chubon 1994), reaching nevertheless similar levels of well-being. Third, the Pearson correlation coefficient between the point estimates obtained under both methods is 0.80 , which should be interpreted as comforting, as long as we use a very different dependent variable for measuring well-being and we get a quite consistent ranking. Nevertheless, it is worth mentioning that the differences according to the way in which welfare is measured are larger than those reported by Zaidi and Burchardt (2005) for the UK, who obtained similar findings both for the subjective question on ability to make ends meet and for the approach based on households' items. Fourth, the results obtained are roughly in line with the estimates of the few countries with data on the issue using similar surveys (as the cases of Ireland, the UK or Spain, for which there are several works reviewed in Table 2). Finally, although it is difficult to extrapolate a clear pattern from the results, several facts can be highlighted. For example, in both estimations Scandinavian countries, headed by Norway, lead the ranking of the costs of disability, while at the bottom, in general, we find Eastern European.

Finally, we conclude this subsection presenting the estimates of the costs of having a disabled member living alone in the household in absolute monetary terms (Euros at 2010 prices in Power Purchasing Parity, PPP, taking as price reference the European Union as a whole). These values are obtained as the product of the percentages (Fig. 1) and the median income of households with a disabled member living alone (Table 4). ${ }^{21}$

The results presented above suggest the existence of important variations in the cost of disability for households across the 31 European countries included in this study. Although fully and causally disentangle the drivers of these differences probably requires a separate research work that falls out of the scope of this paper, we try to offer some additional explanations for this pattern below.

A first possible explanation is that part of the estimated differences might be related to measurement problems because of the subjective nature of the disability data used in the analysis. As can be inferred from Table 1, the percentage of adult population reporting to have strong limitations widely varies across countries. It could be argued that some of these differences are related to the disparate concept of disability applied by the respondent when filling in the survey questionnaire (and not to their "true" degree of disability). In this respect, Jürges's (2007) cross-national differences in selfreported health tend to be higher than the differences in true health (measured by diagnosed conditions), while the degree of dissonance between the two is different among countries, with Danish and Swedish having a tendency to overrate their health statuses compared with Germans, for example, who have a tendency to underrate it. If that were the case, those countries with high "statistical" (i.e., self-reported) disability rates would show a lower cost of disability, because part of the population considered to be disabled is not really so, showing therefore zero or a very low extra cost and thereby bringing down the estimated average cost of disability. However, the Pearson correlation coefficient between the share of people over 16 years old with strong limitation in their daily activities and the cost of disability using either of the

\footnotetext{
21 Given that the well-being index using the PCA is used as a variable in the econometric model, we have computed the standard errors using bootstrapping procedures, obtaining essentially the same results as the ones reported here.
} 

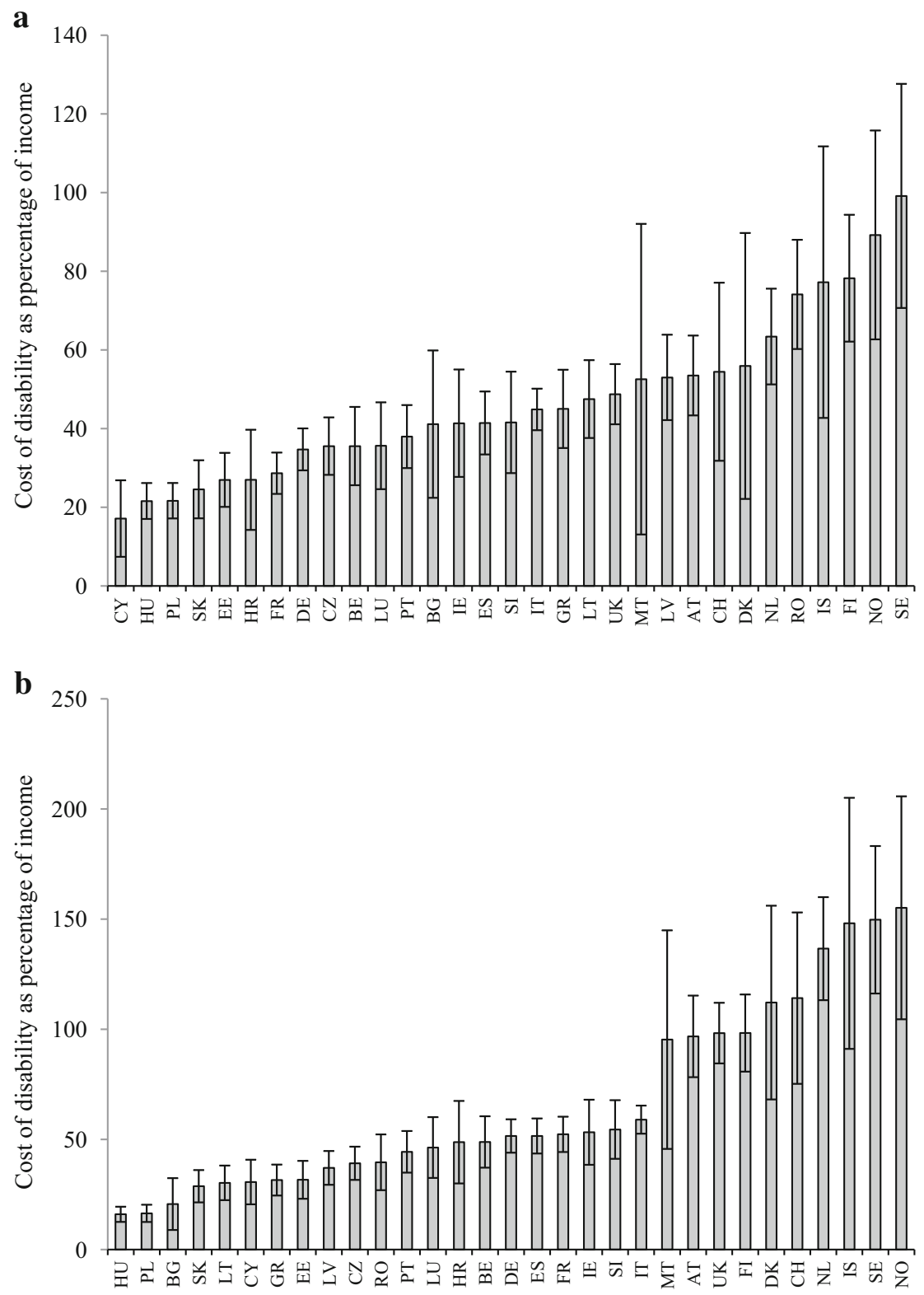

Fig. 1 Estimated cost of a household member with disability living with no other adults for households across 31 European countries (\% of household income). a Estimated cost of a member with disability with welfare based on ability to make ends meet. b Estimated cost of a member with disability with welfare based on PCA of household assets. Notes interval confidences calculated at the $95 \%$ confidence level using the delta method-Acronyms follow the list of acronyms used by the European Union, presented in Table 1. Source: Authors' analysis from EU-SILC 2007 and 2012 
Table 4 Estimated cost of a household member with disability living with no other adults across 31 European countries (Euros per year at 2010 prices in Power Purchasing Parity)

\begin{tabular}{|c|c|c|c|c|}
\hline \multirow[t]{2}{*}{ Country } & \multicolumn{2}{|c|}{$\begin{array}{l}\text { Method with welfare based on ability } \\
\text { to make ends meet }\end{array}$} & \multicolumn{2}{|c|}{$\begin{array}{l}\text { Method with welfare based on PCA } \\
\text { analysis of household assets }\end{array}$} \\
\hline & Point estimate & $\begin{array}{l}95 \% \text {-level } \\
\text { confidence interval }\end{array}$ & Point estimate & $\begin{array}{l}95 \% \text {-level } \\
\text { confidence interval }\end{array}$ \\
\hline Austria (AT) & 16,321 & $13,197-19,444$ & 9019 & $7307-10,731$ \\
\hline Belgium (BE) & 14,550 & $11,073-18,026$ & 10,588 & $7622-13,554$ \\
\hline Bulgaria (BG) & 524 & $225-822$ & 1042 & $567-1517$ \\
\hline Switzerland $(\mathrm{CH})$ & 16,513 & $10,885-22,142$ & 7,875 & $4600-11,150$ \\
\hline Cyprus (CY) & 4918 & $3294-6543$ & 2745 & $1185-4306$ \\
\hline Czech Republic (CK) & 3044 & $2458-3631$ & 2762 & 2194-3331 \\
\hline Germany (DE) & 6802 & $5801-7803$ & 4578 & $3874-5282$ \\
\hline Denmark (DK) & 20,555 & $12,494-28,617$ & 10,250 & $4,053-16,447$ \\
\hline Estonia (EE) & 1785 & $1300-2271$ & 1520 & $1132-1,907$ \\
\hline Spain (ES) & 7246 & $6127-8365$ & 5820 & $4696-6,945$ \\
\hline Finland (FI) & 14,425 & $11,855-16,995$ & 11,480 & $9114-13,847$ \\
\hline France (FR) & 8761 & $7417-10,105$ & 4797 & $3917-5677$ \\
\hline Greece (GR) & 3635 & $2825-4445$ & 5185 & $4038-6332$ \\
\hline Croatia (HR) & 2309 & $1422-3196$ & 1277 & $674-1881$ \\
\hline Hungary (HU) & 1294 & 1015-1574 & 1746 & $1376-2115$ \\
\hline Ireland (IE) & 10139 & $7326-12,951$ & 7874 & $5274-10,474$ \\
\hline Iceland (IS) & 24503 & $15,073-33,934$ & 12,777 & $7064-18,489$ \\
\hline Italy (IT) & 10,562 & 9419-11,704 & 8033 & 7087-8979 \\
\hline Lithuania (LT) & 1816 & $1345-2,287$ & 2848 & $2255-3442$ \\
\hline Luxembourg (LU) & 13,182 & $9254-17,110$ & 10,138 & $6997-13,279$ \\
\hline Latvia (LV) & 1852 & 1469-2235 & 2648 & $2106-3,191$ \\
\hline Malta & 13,086 & $6274-19,898$ & 7216 & $1794-12,638$ \\
\hline Netherlands (NL) & 20,681 & $17,140-24,221$ & 9,597 & $7754-11,439$ \\
\hline Norway (NO) & 37,445 & $25,228-49,662$ & 21,533 & $15,125-27,941$ \\
\hline Poland (PL) & 1386 & 1055-1716 & 1,826 & 1446-2207 \\
\hline Portugal (PT) & 3,128 & $2462-3794$ & 2676 & 2111-3241 \\
\hline Romania (RO) & 1,238 & $842-1634$ & 2316 & $1882-2750$ \\
\hline Sweden (SE) & 23,012 & $17,866-28,158$ & 15,239 & $10,860-19,617$ \\
\hline Slovenia (SI) & 5652 & $4272-7032$ & 4310 & $2972-5647$ \\
\hline Slovakia (SK) & 2453 & 1828-3078 & 2095 & $1465-2725$ \\
\hline United Kingdom (UK) & 18,438 & $15,857-21,018$ & 9144 & $7708-10,579$ \\
\hline
\end{tabular}

Source: Authors' analysis from EU-SILC 2007 and 2012 and Eurostat database

two methods applied here are remarkably low ( -0.06 and -0.03 , respectively). Thus, we conclude that although measurement error might be one of the factors behind the observed differences, is not likely to be the main driver of them. 
The second possible explanation considered is related to one of the methodologies used, the so-called subjective-indirect. As explained in Sect. 3, this methodology compares the difficulty that different households have in making ends meet with their current incomes, interpreting these differences in the ability of otherwise identical households but for the presence of one or more members with disabilities in terms of the cost of the disability. It can be argued that the ability to make ends meet is affected by the expectations of the households of what they are entitled to do (what they want to do). If that is so, then societies with a strong feeling of equal rights for disabled people and a strong culture of equality might breed higher expectations and demands in households with disabled members and correspondingly higher disability costs. This could explain the high cost of disability for households in countries with a strong socialdemocratic tradition of equal opportunities such as Denmark, Sweden and Norway. This argument seems sound, but in order to serve as a reasonable explanation of the observed differences in disability costs, such differences should only be present in the subjective-indirect method, and not in the second objective method, and that is not the case. Therefore, we must also reject this second explanation as a prime hypothesis for the observed differences in cost. ${ }^{22}$

A third possible explanation arises from the observed positive correlation between the cost of disability and GDP per capita across countries. The higher cost of disability in high-income countries (on average) might be due to the higher opportunity cost of not being able to take advantage of a full involvement in market activities -in both labour and capital markets- or even income transfers from other households in highproductivity societies (Figs. 2 and 3). This factor could be particularly important for working-age population, not only for the people with disabilities themselves but also for their relatives. As long as disability and well-being -as measured here-include quite longstanding elements, the cost of disability could capture the cumulative opportunity cost of having strong limitations in the market.

Finally, it is worth mentioning the existence of two final important cross-country relationships (Figs. 2 and 3). The first one is the positive relationship between the effort on disability in terms of social spending and the cost of disability. ${ }^{23}$ Thus, countries with a higher level of public expenditure on disability tend to report, on average, also higher costs of disability. Although it is beyond the scope of this work to disentangle this relationship, it might be possible that the higher level of resources devoted to this area is -at least, partially- a response aiming to compensate the higher cost of disability in these countries. Second, it is also worth mentioning the existence of a relatively strong positive correlation between in-kind social benefits on disability and the mentioned cost of disability across countries. In this respect, it should be kept in mind that in-kind benefits are not included in the concept of income available in the

\footnotetext{
22 The effect of income on subjective well-being can be also affected by potential incomparability of response scales across countries (Kapteyn et al. 2013), with a possible impact on the cost of disability. However, again, we rule out this explanation as it would only apply to the subjective-indirect approach.

23 Social spending on disability includes those benefits that (a) provide an income to persons below standard retirement age as established in the reference scheme whose ability to work and earn is impaired beyond a minimum level laid down by legislation by a physical or mental disability; (b) provide rehabilitation services specifically required by disabilities;(c) provide goods and services other than medical care to disabled people. The figure includes economic integration of the handicapped (Eurostat 2012).
} 

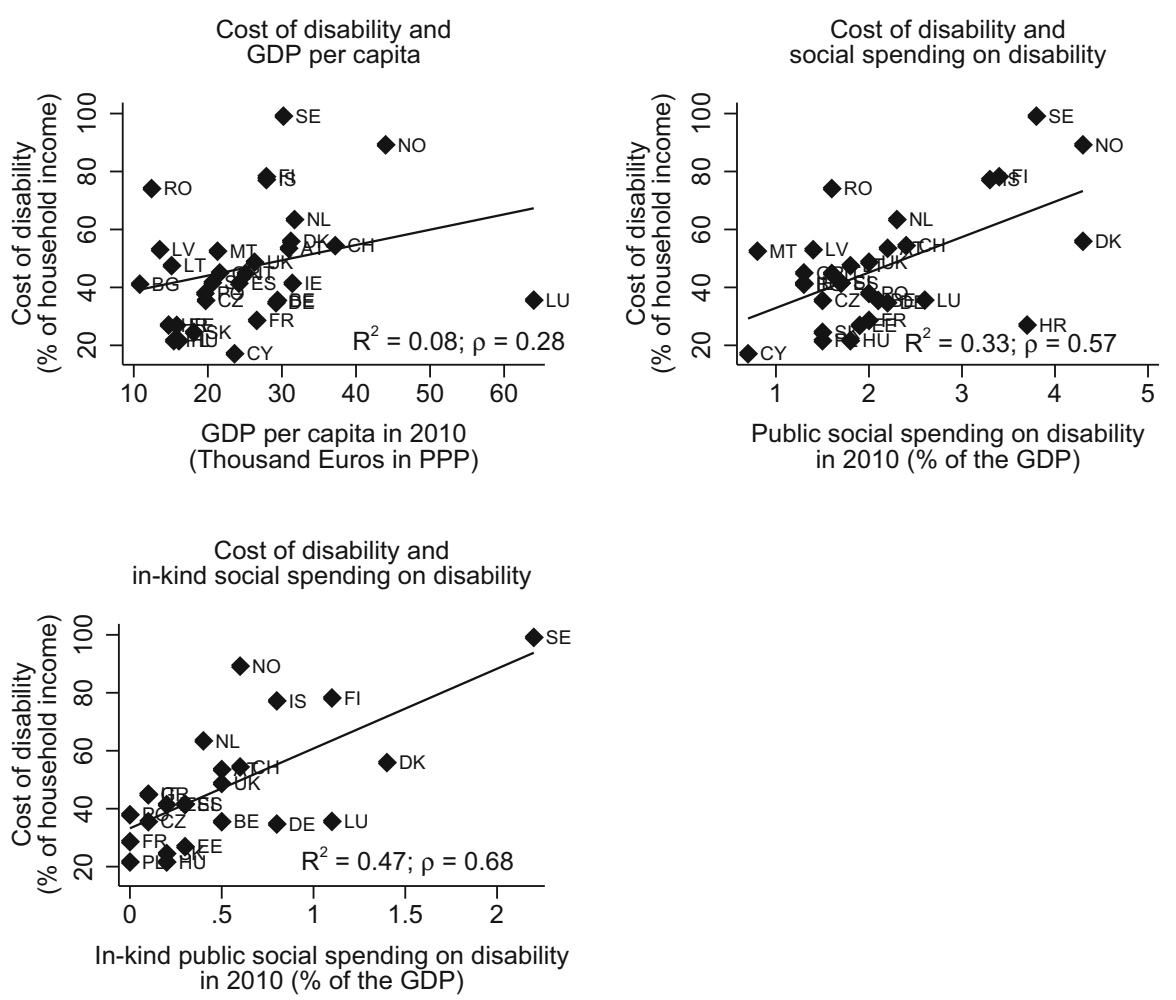

Fig. 2 Cross-country correlations between the cost of a household member with disability living alone (with welfare based on ability to make ends meet) and GDP per capita, social spending on disability and in-kind social spending on disability. Note Acronyms follow the list of acronyms presented in Table 1. Source: Authors' analysis from EU-SILC 2007 and 2012, Eurostat and OECD databases

EU-SILC and, in this respect, this omission could probably result in an overestimation of the true cost of disability across countries. A last remark to be made in this section refers to Luxembourg and its position at the bottom of the rankings. The low cost in the Grand Duchy can be interpreted as a result of an extremely high per capita income, closely related to the well-known particularities of the country, which makes the cost of disability a lighter load for national households.

As we have mentioned in Sects. 1 and 2, it is hard to compare these results with the ones reported in previous literature since the methodologies, databases and definitions of both disability and well-being are highly heterogeneous. However, the results seem to be in line with those found in studies employing reasonably similar approaches for the UK (Kuklys 2005; Zaidi and Burchardt 2005), Ireland (Indecon 2004; Cullinan et al. 2011a,b) or Spain (Braña and Antón 2011). Also, the results obtained by She and Livermore (2007) for the United States and Saunders (2007) for Australia seem to be consistent with the range of estimates obtained here. Lastly, an inspection of the findings reported in Table 2 (particularly, after looking at estimated cost of disability reported by Braithwaite and Mont 2009, for Vietnam and Bosnia) seem to be coherent with a cost of disability that rises with the level of development of the country. 

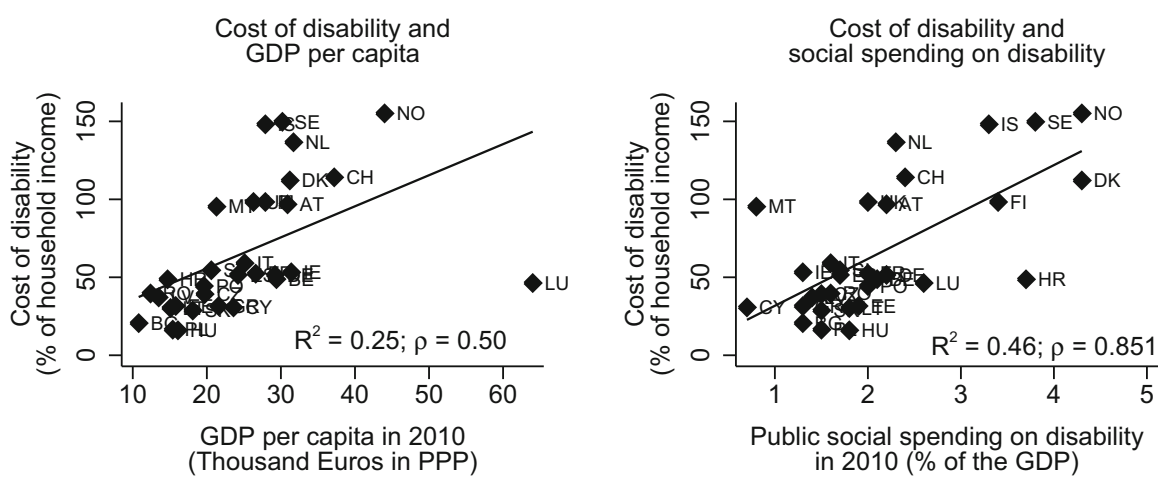

Cost of disability and in-kind social spending on disability

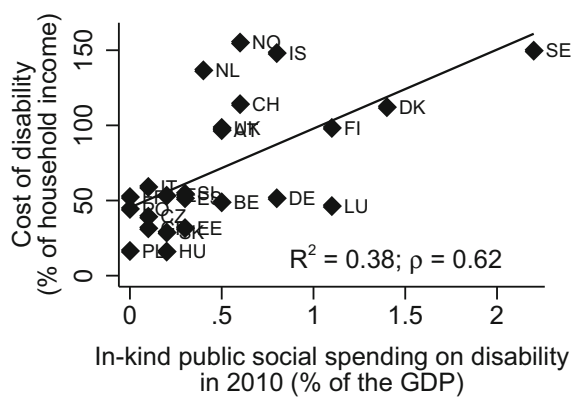

Fig. 3 Cross-country correlations between the cost of a household member with disability living alone (with welfare based on PCA of household assets) and GDP per capita, social spending on disability and in-kind social spending on disability. Note Acronyms follow the list of acronyms presented in Table 1. Source: Authors' analysis from EU-SILC 2007 and 2012, Eurostat and OECD databases

\section{Conclusion}

The aim of this paper has been to firstly present a comparative analysis of the cost of disability in Europe using the EU-SILC. This study has been based on the so-called standard of living approach, using two different methodologies (one based on selfreported ability to make ends meet and the other associated with access to several items, assets and services). Because of its comparative ambition, the work can also serve to test the usefulness and appropriateness of the standard of living method itself, which so far has provided results that can be reasonably interpreted in economic terms.

The first important finding of this study is that there is a significant diversity in the cost of disability across European countries. The overall pattern show Scandinavian countries at the top of the ranking and Eastern European states at the bottom. The second contribution of the article is related to the discussion of these disparate patterns. After rejecting different hypotheses that could help interpret the results, such as the different expectations of people with disabilities in different countries or problems related to the mismeasurement of disability rates, our analysis suggests that, to a large extent, the cost of disability is related to a larger opportunity cost due to the inability 
to fully take advantage of the participation in market activities of either people with disabilities or their relatives or income transfers from relatives in other households. However, it is also relevant to highlight that the omission of in-kind social benefits in these sorts of surveys might be contributing to overestimate the cost of disability in those countries devoting more resources to compensate the limitations faced by some individuals in their daily activities. Finally, the existence of a relatively high correlation between overall social spending on disability and its cost could suggest that the former is partially a response to the latter.

The results presented so far leave the authors (and probably the readers) with a bittersweet sensation. On one side, the application of a given methodology, until now only applied to a single country, to a common database and a large number of countries has shown interesting patterns in terms of the cost of disability, a novel result by itself that the authors have explained by resorting to different hypotheses. Nevertheless, it has to be acknowledged that the explanations so far offered might not be fully convincing. On the other side, the diversity of the cost estimated-depending on the country-might only show that the method is not as useful as it has been considered until now. Obviously, when estimates are produced for a single country there is no point of comparison to see whether the results are reasonable or not. The comparative analysis opens such a perspective.

As a final reflection we would like to point that there is a long way to go in the study of the cost of disability in both developed and developing countries. Disability is a common phenomenon in Europe and it is likely to be a more and more important problem in the coming decades because of the ageing of the population pyramid. In this sense, several lines for further research can be suggested. First, the findings could be reinforced by the use of databases that, apart from income, contain more detailed and objective information on the health conditions of individuals (even if self-reported), information which was not available when writing this paper. Second, research on the costs of disabilities could profit from the joint use of alternative methods of estimation (without being restricted to the use of a single approach), combining quantitative and qualitative methods. Thirdly, further research trying to deepen in the causal drivers of differences in costs of disability across countries should be encouraged.

Open Access This article is distributed under the terms of the Creative Commons Attribution 4.0 International License (http://creativecommons.org/licenses/by/4.0/), which permits unrestricted use, distribution, and reproduction in any medium, provided you give appropriate credit to the original author(s) and the source, provide a link to the Creative Commons license, and indicate if changes were made.

\section{References}

Asghar Z, Tania B (2005) Comparing incomes when needs differ equivalization for the extra costs of disability in the UK. Rev Income and Wealth 51(1):89-114

Baetschmann G, Staub KE, Winkelmann R (2015) Consistent estimation of the fixed effects ordered logit model. J R Stat Soc Ser A Stat Soc 178(3):685-703

Berthoud R, Lakey J, McKay S (1993) Economic problems of disabled people. Policy Studies Institute, London

Bollinger CR (2001) Response error and the union wage differential. Southern Econ J 68(1):60-76 
Braithwaite J, Mont D (2009) Disability and poverty: a survey of world bank poverty assessments and implications. ALTER, Eur J Disability 3(3):219-232

Card D (1996) The effect of unions on the structure of wages: a longitudinal analysis. Econometrica 64(4):957-979

Chubon RA (1994) Social and psychological foundations of rehabilitation. Charles C Thomas, Springfield

Cullinan J, Gannon B, O'Shea E (2011) The welfare implications of disability for older people in Ireland, European Journal of Health Economics, published on line: 08 October 2011. doi:10.1007/ s10198-011-0357-4

Cullinan J, Gannon B, Lyons S (2011) Estimating the extra cost of living for people with disabilities. Health Econ 20(5):582-599

Dieleman JL, Templin T (2014) Random-effects, fixed-effects and the within-between specification for clustered data in observational health studies: a simulation study. PLoS One 9(10):e110257

European Commission (2010): Communication from the Commission to the European Parliament, the Council, the European Economic and Social Committee and the Committee of the Regions. European Disability Strategy 2010-2020: A Renewed Commitment to a Barrier-Free Europe, Brussels, 15.11.2010; $\operatorname{COM(2010)} 636$ final

Eurostat (2012) ESSPROS manual and user guidelines the european system of integrated social protection statistics (ESSPROS). Publications Office of the European Union, Luxembourg

Filmer D, Pritchett LH (2001) Estimating wealth effects without expenditure data-or tears: an application to educational enrollments in states of India. Demography 38(1):115-132

Francisco-Javier B, José-Ignacio A (2011) Pobreza, discapacidad y dependencia en España. Papeles de Economía Española 129:14-26

Freeman RB (1984) Longitudinal analyses of the effects of trade unions. J Labor Econ 1(1):1-26

Indecon (2004): Cost of Disability Research Project, Dublin: National Disability Authority. Available at http://nda.ie/File-upload/Indecon-Report-on-the-Cost-of-Disability.pdf [last accessed $28^{\text {th }}$ March 2016]

Jones A, O’Donnell O (1995) Equivalence scales and the costs of disability. J Publ Econ 56(2):273-289

Jürges H (2007) True health vs response styles: exploring cross-country differences in self-reported health. Health Econ 16(2):163-178

Kapteyn A, Smith JP, Van Soest A (2013) Are Americans really less happy with their incomes? Rev Income and Wealth 59(1):44-65

Kuklys W (2005) Amartya Sen's capability approach., Theoretical insights and empirical applications. Springer Verlag, Heidelberg

Lancaster KJ (1966) A new approach to consumer theory. J Political Econ 74(2):132-157

Martin J, White A (1988) Office of population censuses and surveys report 2, the financial circumstances of disabled adults living in private households. Her Majesty's Stationary Office, London

Matthews A, Truscott P (1990) Disability, household income and expenditure: a follow-up survey of disabled adults in the Family Expenditure Survey. Research Report No. 2, Department of Social Security

Mitra S, Findley PA, Sambamoorthi U (2009) Health care expenditures of living with a disability: Total expenditures, out-of-pocket expenses, and burden, 1996 to 2004. Arch Phys Med Rehabil 90(9):15321540

Muris C (2016) Estimation in the fixed effects ordered logit model. Rev Econ Stat. doi:10.1162/ REST_a_00617

Organisation for Economic Co-operation and Development (OECD) (2003) Transforming Disability into ability. OECD, Policies to promote work and income security for disabled people, Paris

Organisation for Economic Co-operation and Development (OECD) (2010) Sickness, disability and work. OECD, Breaking the barriers, Paris

Saunders P (2007) The costs of disability and the incidence of poverty. Aust J Soc Issues 42(4):461-480

Sen A (2004) Disability and justice, lecture delivered at the Disability and Inclusive Development Conference, the World Bank, Washington, D.C., $1^{\text {st }}$ December 2004. Available at http://siteresources. worldbank.org/DISABILITY/214576-1092421729901/20291152/Amartya_Sen_Speech.doc [last accessed $17^{\text {th }}$ March 2011]

Sen A (1985) Commodities and capabilities. North Holland, Amsterdam

Sen A (1987) On Ethics and economics. Basil Blackwell, Oxford

She P, Livermore GA (2007) Material hardship, poverty, and disability among working-age adults. Soc Sci Quart 88(4):970-989 
Stapleton D, Protik A, Stone C (2008) Review of international evidence of the cost of disability, Working Paper No. 542, Department for Work and Pensions

Swaffield JK (2001) Does measurement error bias fixed-effects estimates of the union wage effect? Oxford Bull Econ Stat 63(4):437-457

Tibble M (2005) Review of existing research on the extra costs of disability. Working Paper No. 21, Department for Work and Pensions

Wilkinson-Meyers L, Brown P, McNeill R, Patston P, Dylan S, Baker R (2010) Estimating the additional cost of disability: beyond budget standards. Soc Sci Med 71(10):1882-1889

Wood C, Grant E (2010) Counting the cost. Demos, London

Wooldridge J (2010) Econometric analysis of cross-section and panel data, 2nd edition. The MIT Press, London

World Health Organization (WHO) (2011) World Report on Disability. World Health Organization, Geneva 